\title{
NUCLEAR EMISSIONS FROM TITANIUM HYDRIDE/DEUTERIDE INDUCED BY POWERFUL PICOSECOND LASER BEAM
}

\author{
A. S. ROUSSETSKI \\ P.N. Lebedev Physical Institute \\ Russian Academy of Sciences, 53 Leninsky prospect, 119991 Moscow, Russia \\ E-mail: rusets@x4u.lebedev.ru
}

A. G. LIPSON

Institute of Physical Chemistry

Russian Academy of Sciences, Russia

V. P. ANDREANOV

Research Institute of Pulse Technique

Ministry of Atomic Energy, Russia

\begin{abstract}
The emission of nuclear particles (protons, deuterons, neutrons and alpha particles) was detected during the irradiation of different targets, including $30 \mu \mathrm{m}$ thick $\mathrm{Ti}$ metal and TiD foils, as well as $\mathrm{CH}_{2}$-film, by an intense picosecond laser beam $\left(I=2.0 \times 10^{18} \mathrm{~W} / \mathrm{cm}^{2}, \lambda=1.053 \mu \mathrm{m}\right)$. The nominally pure Ti metal target contained some adsorbed hydrogen $\left(\mathrm{TiH}_{x}\right)$. It was shown, that the main component of emitted particles is consisted of protons/deuterons $\left(N_{\mathrm{p}} \sim 10^{11} \mathrm{sr}^{-1}\right.$ per pulse) accelerated up to the energy $E_{\mathrm{p}} \leq 0.8 \mathrm{MeV}$. Energetic $3 \mathrm{MeV}$ protons and neutrons ( $\sim 10^{4}$ per pulse into $4 \pi \mathrm{sr}$.) were detected in the case of $\mathrm{TiD}_{x}$ experiments, and both can be considered as a signature of the dd-fusion in the target. The emission of $\alpha$-particles ( $E_{\alpha} \geq 10 \mathrm{MeV}, N_{\alpha} \sim 10^{4} \mathrm{sr}^{-1}$ per pulse), never previously observed in experiments with solid (nonmetal-hydride) targets, was detected in the case of $\mathrm{TiH}_{x}$ and $\mathrm{TiD}_{x}$ foils. The emission of ions with mass $A>4\left(N_{i} \sim 10^{4}\right.$ to $10^{5} \mathrm{sr}^{-1}$ per pulse) has also been detected on $\mathrm{TiD} / \mathrm{H}$ targets. The energy of these ions, estimated with the shielding filters was found to be $E_{\mathrm{i}} \geq 3.0 \mathrm{MeV}$ per nucleon.
\end{abstract}

\section{Introduction}

Laser-produced plasmas are known to be a source of fast ions with energies on the order of a few $\mathrm{MeV}$ per nucleon when the laser intensity is $\geq 10^{18} \mathrm{~W} / \mathrm{cm}^{2}$ ) as reported in the literature. ${ }^{1-8}$ The investigation of the spatial and spectral characteristics of this emission may help in the understanding and the application of laser-plasma acceleration of charged particles. These ions may be also used in different applied fields; for example, in the initiation of laser thermonuclear fusion. ${ }^{1}$

The experimental goal of present work was the investigation of the characteristics of charged particle emission, produced by the interaction of an intense laser 


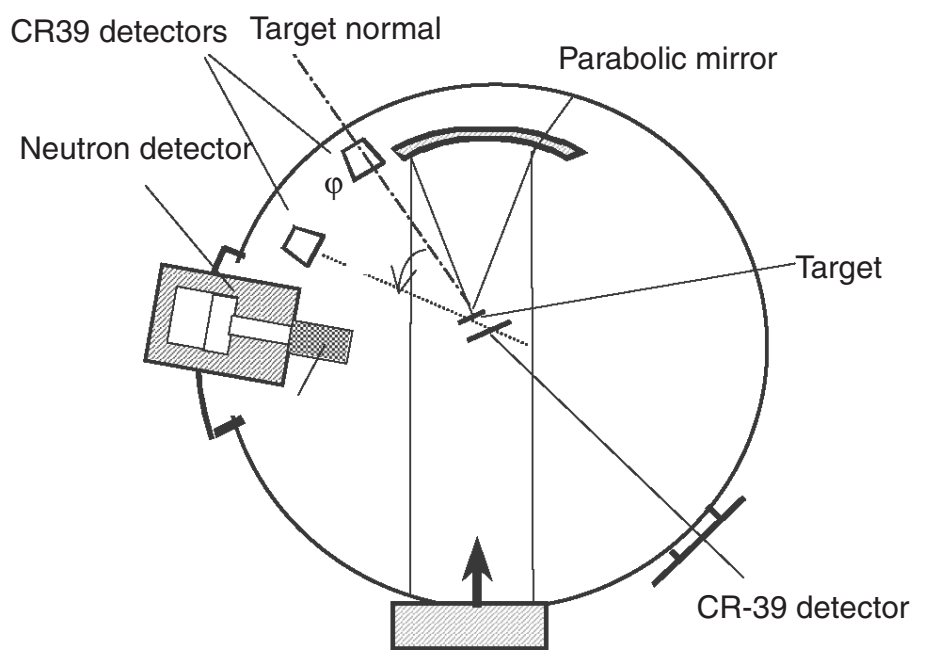

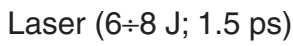

Figure 1. The scheme of experimental setup.

beam with the surface of $\mathrm{TiH}_{x}, \mathrm{TiD}_{x}$ and $\mathrm{CH}_{2}$ targets, as well as the possibility of initiation of dd-fusion in materials containing deuterium by laser irradiation.

In the present work, we used a laser intensity on the target surface of 1-2 $\times 10^{18} \mathrm{~W} / \mathrm{cm}^{2}$. We measured the fluxes of charged particles emitted from the of $\mathrm{TiH}_{x}, \mathrm{TiD}_{x}$ and $\mathrm{CH}_{2}$ targets using CR-39 plastic track detectors with different filters.

\section{Experimental Technique}

The experiments were carried out with the use of the PROGRESS-P laser, ${ }^{9}$ operating at a wavelength of $1.054 \mu \mathrm{m}$ with a pulse duration of $1.0-1.6 \mathrm{ps}$ and an energy of 6-8 J. A schematic of the experiment is presented in Fig. 1. The initial laser beam diameter was $180 \mathrm{~mm}$, and this beam was focused into a spot with diameter $<15 \mu \mathrm{m}$ using an $\mathrm{f} / 1.1$ parabolic mirror. The laser beam was incident on the sample at an angle of $45^{\circ}$. The maximum intensity on target was $1-2 \times 10^{18} \mathrm{~W} / \mathrm{cm}^{2}$. As was shown in Ref. 4, the pre-pulse plays the important role in the processes of interaction of laser beam with solid targets, and the parameters of pre-pulse may influence on the ion acceleration. In our experiment the intensity of pre-pulse was less than $10^{-3}$ of main pulse.

We used both $30 \mu \mathrm{m}$ titanium metal foil and titanium deuteride $\left(\mathrm{TiD}_{x}\right)$ as targets. The titanium deuteride sample was prepared by electrolysis of a Ti metal foil in $0.1 \mathrm{M}$ solution of $\mathrm{D}_{2} \mathrm{SO}_{4}$ for $2.5 \mathrm{~h}$ at a current density $\sim 50 \mathrm{~mA} / \mathrm{cm}^{2}$. It is important to note that the $\mathrm{Ti}$ metal foil contained some amount of absorbed hydrogen $\left(\mathrm{TiH}_{x}\right)$, which was also presented in $\mathrm{TiD}_{x}$ target. In one experiment we used a $\mathrm{CH}_{2}$ film ( $35 \mu \mathrm{m}$ thick) as a target. 


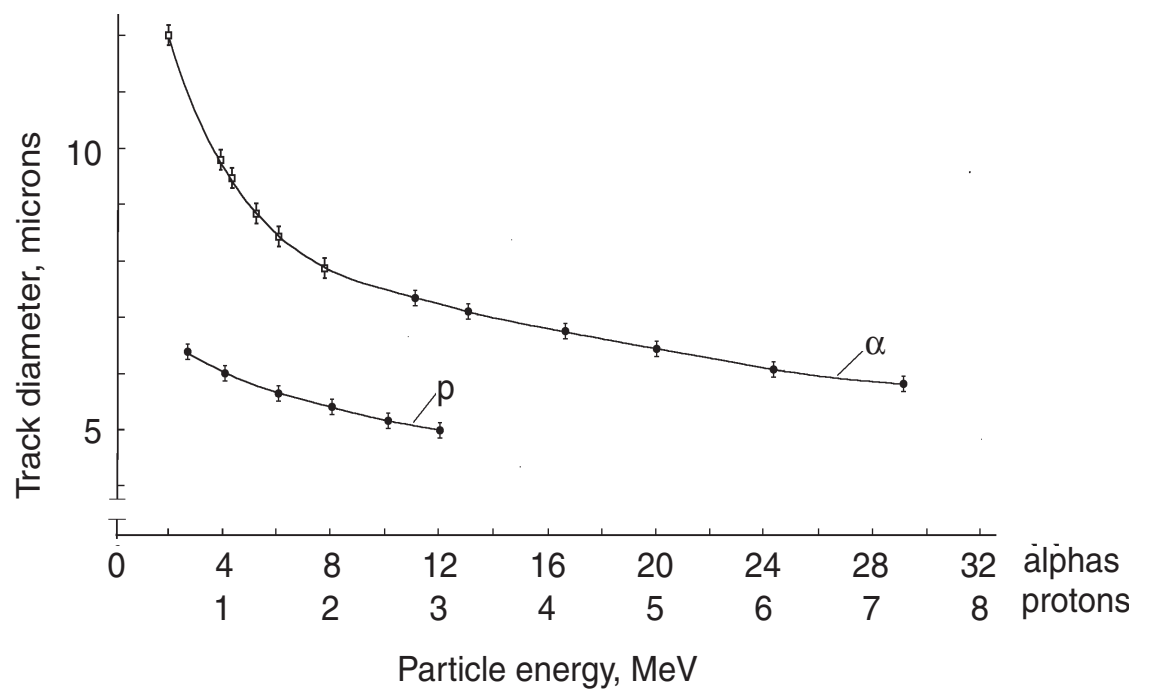

Figure 2. The calibration dependence of track diameters of alpha-particles and protons on their energy, $(\square)$ : radioactive alpha-sources; $(\bullet)$ : particle beams.

The charged particle emission was measured using CR-39 plastic track detectors with the shielding filters of different thickness. Activated In-foils were employed for the neutron emission detection. The CR-39 plastic track detector consists of a polymer plate $\left(\mathrm{C}_{12} \mathrm{H}_{18} \mathrm{O}_{7}\right)$ with the density $1.3 \mathrm{~g} / \mathrm{cm}^{3}$. In this work we used CR39 produced by Fukuvi Chemical Industry Co. of Japan. The tracks of particles became visible after etching and then were inspected under a microscope.

These detectors were calibrated with $\alpha$-sources (in the range of 1.6-7.7 MeV), by monoenergetic cyclotron $\alpha$-beams (in the energy range of $10.0-30.0 \mathrm{MeV}$ ), and also using proton beams from a Van de Graaf accelerator with energies in the range $0.75-$ $3.0 \mathrm{MeV}$. After beam exposure the detectors were etched in $6 \mathrm{~N} \mathrm{NaOH}$ at $t=70^{\circ} \mathrm{C}$ for $7 \mathrm{~h}$ and inspected using a (MBI-9) optical microscope. For the particles normally incident on the detector, the tracks are the cones which diameters that depend on the particle energy. The results of the calibration (i.e. the dependence of track diameters on particle energy) are presented in Fig. 2.

In our experiments we used both open detectors, and detector with filters such as $\mathrm{Al}$ foil (11, 33 and $66 \mu \mathrm{m}$ thick) and $\mathrm{Cu}$ foil ( 25 and $50 \mu \mathrm{m}$ thick). Some detectors were placed in front of irradiated surface at angles of $\varphi=0^{\circ}$ and $30^{\circ}$ to the target normal, at the distance $R=20 \mathrm{~cm}$ from the focus spot on the target. One detector was placed behind the target $\left(\varphi=180^{\circ}\right)$ at the distance of $R=4 \mathrm{~cm}$. Using detectors with filters we can to separate different groups of charged particles from each other, and also estimate the associated angular distribution of the emission. 


\section{Results and Discussion}

The results of measurements of charged particle fluxes in five groups of experiments are presented in Table 1. As one can see from this table, there are three groups of charged particles emitted from the targets. According to the calibration (Fig. 2) the track diameters of protons are less than $7 \mu \mathrm{m}$. Alpha-particles with energies in

Table 1. Summary of results from laser irradiation experiments.

\begin{tabular}{|c|c|c|c|c|c|c|c|c|}
\hline \multirow[t]{2}{*}{ target } & \multirow{2}{*}{$\begin{array}{l}E_{L} \\
(\mathrm{~J})\end{array}$} & \multicolumn{2}{|c|}{ detector } & \multirow{2}{*}{$\begin{array}{c}\text { filter } \\
\mu\end{array}$} & \multirow[b]{2}{*}{$\begin{array}{l}\text { energy } \\
\text { estimate } \\
\text { before } \\
\text { filter } \\
E_{\mathrm{p}} / E_{\mathrm{d}} / E_{\alpha} \\
(\mathrm{MeV})\end{array}$} & \multirow{2}{*}{$\begin{array}{l}n_{\mathrm{p}(\mathrm{d})} \\
\left(\mathrm{sr}^{-1}\right)\end{array}$} & \multirow{2}{*}{$\begin{array}{c}n_{\alpha} \\
\left(\mathrm{sr}^{-1}\right)\end{array}$} & \multirow{2}{*}{$\begin{array}{c}n_{\mathrm{i}} \\
\left(\mathrm{sr}^{-1}\right)\end{array}$} \\
\hline & & index & $\begin{array}{l}R(\mathrm{~cm}) \\
/ \varphi^{\circ}\end{array}$ & & & & & \\
\hline \multirow{5}{*}{$\begin{array}{l}\mathrm{TiD}_{x} \\
30 \mu \mathrm{m}\end{array}$} & \multirow[t]{5}{*}{7.3} & $1-1$ & $4 / 180$ & $\mathrm{Ti}, 30$ & $>2 / 2.4 / 8$ & $7 \times 10^{5}$ & - & - \\
\hline & & $1-2$ & $20 / 30$ & none & $>0.1$ & $2.3 \times 10^{7}$ & - & - \\
\hline & & $1-3$ & $20 / 0$ & $\mathrm{Al}, 11$ & $>0.8 / 1.0 / 3.2$ & $10^{4}$ & $2.4 \times 10^{4}$ & $10^{5}$ \\
\hline & & $1-4$ & $20 / 30$ & $\mathrm{Al}, 66$ & $>2.6 / 3.4 / 10.5$ & $2.2 \times 10^{4}$ & $3.6 \times 10^{4}$ & $2.1 \times 10^{5}$ \\
\hline & & $1-5$ & $20 / 0$ & $\mathrm{Cu}, 25$ & $>2.4 / 3.0 / 9.6$ & $<2 \times 10^{3}$ & $1.8 \times 10^{4}$ & \\
\hline \multirow{5}{*}{$\begin{array}{c}\mathrm{TiH}_{x} \\
30 \mu \mathrm{m}\end{array}$} & \multirow[t]{5}{*}{6.1} & $2-1$ & $4 / 180$ & $\mathrm{Ti}, 30$ & $>2 / 2.4 / 8$ & $1 \times 10^{7}$ & - & - \\
\hline & & $2-2$ & $20 / 30$ & none & $>0.1$ & $>10^{11}$ & - & - \\
\hline & & $2-3$ & $20 / 0$ & $\mathrm{Al}, 11$ & $>0.8 / 1.0 / 3.2$ & $1.4 \times 10^{4}$ & $1.6 \times 10^{4}$ & $1.4 \times 10^{4}$ \\
\hline & & $2-4$ & $20 / 30$ & $\mathrm{Al}, 66$ & $>2.6 / 3.4 / 10.5$ & $4.0 \times 10^{3}$ & $2 \times 10^{4}$ & $10^{4}$ \\
\hline & & $2-5$ & $20 / 0$ & $\mathrm{Cu}, 25$ & $>2.4 / 3.0 / 9.6$ & $<2 \times 10^{3}$ & $6 \times 10^{3}$ & $1.2 \times 10^{4}$ \\
\hline \multirow[t]{5}{*}{$\begin{array}{c}\mathrm{TiD}_{x} \\
30 \mu \mathrm{m}\end{array}$} & \multirow[t]{5}{*}{7.3} & $3-1$ & $4 / 180$ & $\begin{array}{l}\mathrm{Ti}+\mathrm{Cu} \\
30+25\end{array}$ & $>3.3 / / 4.7 / 13.2$ & $6.9 \times 10^{2}$ & $4.5 \times 10^{2}$ & $1.8 \times 10^{3}$ \\
\hline & & $3-2$ & $20 / 30$ & $\mathrm{Al}, 11$ & $>0.8 / 1.0 / 3.2$ & $2 \times 10^{3}$ & $10^{4}$ & $2.4 \times 10^{4}$ \\
\hline & & $3-3$ & $20 / 0$ & $\mathrm{Al}, 11$ & $>0.8 / 1.0 / 3.2$ & $2 \times 10^{3}$ & $6 \times 10^{3}$ & $8 \times 10^{3}$ \\
\hline & & $3-4$ & $20 / 0$ & $\mathrm{Al}, 33$ & $>1.7 / 2.4 / 6.8$ & $6 \times 10^{3}$ & $1.4 \times 10^{4}$ & $1.2 \times 10^{4}$ \\
\hline & & $3-5$ & $20 / 30$ & $\mathrm{Cu}, 50$ & $>3.8 / 5.3 / 15.2$ & $8 \times 10^{3}$ & $4 \times 10^{3}$ & $10^{4}$ \\
\hline \multirow{5}{*}{$\begin{array}{c}\mathrm{TiH}_{x} \\
30 \mu \mathrm{m}\end{array}$} & \multirow[t]{5}{*}{6.8} & $4-1$ & $4 / 180$ & $\begin{array}{c}\mathrm{Ti}+\mathrm{Cu} \\
30+25\end{array}$ & $>3.3 / / 4.7 / 13.2$ & $<10^{2}$ & $3.7 \times 10^{2}$ & $2.9 \times 10^{4}$ \\
\hline & & $4-2$ & $20 / 30$ & $\mathrm{Al}, 11$ & $>0.8 / 1.0 / 3.2$ & $<2 \times 10^{3}$ & $10^{4}$ & $6 \times 10^{3}$ \\
\hline & & $4-3$ & $20 / 0$ & $\mathrm{Al}, 11$ & $>0.8 / 1.0 / 3.2$ & $2 \times 10^{3}$ & $1.6 \times 10^{4}$ & $1.6 \times 10^{4}$ \\
\hline & & $4-4$ & $20 / 0$ & $\mathrm{Al}, 33$ & $>1.7 / 2.2 / 6.8$ & $4 \times 10^{3}$ & $1.4 \times 10^{4}$ & $4 \times 10^{3}$ \\
\hline & & $4-5$ & $20 / 30$ & $\mathrm{Cu}, 50$ & $>3.8 / 5.3 / 15.2$ & $4 \times 10^{3}$ & $4 \times 10^{3}$ & $1.2 \times 10^{4}$ \\
\hline$\left(\mathrm{Ni}_{2}\right)_{n}$ & 8.2 & $5-1$ & $20 / 0$ & $\mathrm{Al}, 11$ & $>0.8 / 1.0 / 3.2$ & $1.4 \times 10^{4}$ & $<2 \times 10^{3}$ & $1.2 \times 10^{4}$ \\
\hline $35 \mu \mathrm{m}$ & & $5-2$ & $20 / 30$ & $\mathrm{Al}, 11$ & $>0.8 / 1.0 / 3.2$ & $8 \times 10^{3}$ & $<2 \times 10^{3}$ & $2 \times 10^{4}$ \\
\hline
\end{tabular}

$R$ : the distance from the target to the detector; $\varphi$ : the angle between the target normal and the direction to detector; $E_{\mathrm{p}} / E_{\mathrm{d}} / E_{\alpha}$ : the minimum energy of protons, deuterons and $\alpha$-particles crossing the filter; $n_{\mathrm{p}(\mathrm{d})}, n_{\alpha}, n_{\mathrm{i}}$ : the estimations of fluxes of protons(deuterons), $\alpha$-particles and ions with mass $A>4$ on the direction to detector; means, that it is impossible to estimate the flux in this conditions. 


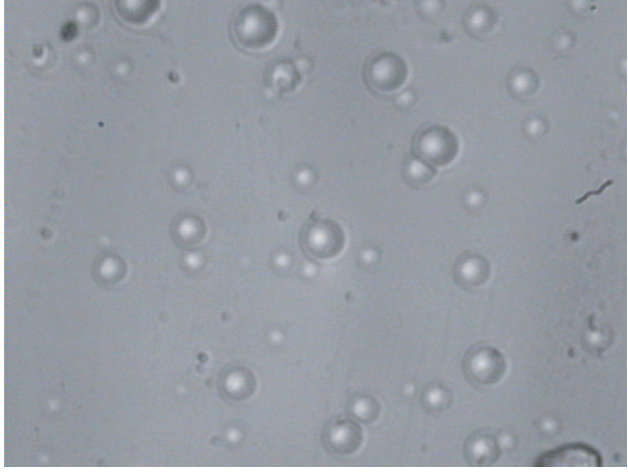

(a)

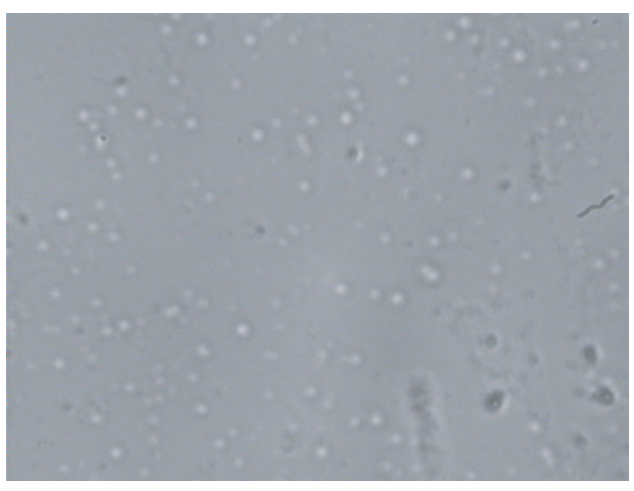

(b)

Figure 3. The photomicrographs of detectors, exposed without the filter behind the target, $R=$ $4 \mathrm{~cm}, \varphi=180^{\circ}$, (a) $\mathrm{TiD}_{x}$ target and (b) $\mathrm{TiH}_{x}$ target.

the range $2-15 \mathrm{MeV}$ produced the tracks with diameters $d=7-12 \mu \mathrm{m}$. We assume that the track diameters $d>12 \mu \mathrm{m}$ are corresponded to the charged particles, more heavy than $\alpha$ 's (mass $A>4$, charge $Z>2$ ). The measurements with the targets including $\mathrm{H} / \mathrm{D}$ showed that the proton (deuteron) emission is anisotropic, and is caused by the large electric field $\left(E \geq 10^{12} \mathrm{~V} / \mathrm{m}\right)$ particle acceleration in the plasma, produced by the laser beam interaction with the target surface. ${ }^{1-8}$ It was found that the main component of emitted particles consists of protons/deuterons $\left(N_{\mathrm{p}} \sim 10^{11} \mathrm{sr}^{-1}\right.$ per pulse) accelerated to energies $E_{\mathrm{p}} \leq 0.8 \mathrm{MeV}$. The significant part $\left(10^{5}-10^{7} \mathrm{sr}^{-1}\right.$ per pulse) of particles accelerated forward have energies in the range $2.0-3.3 \mathrm{MeV}$ for protons, and $2.7-4.4 \mathrm{MeV}$ for deuterons. The flux of particles with such energies accelerated back, opposite the laser beam, do not exceed a value of $10^{3}-10^{4} \mathrm{sr}^{-1}$ per pulse.

The photomicrograph of particle tracks for the cases of detectors placed on the back side of $\mathrm{TiD}_{x}$ and $\mathrm{TiH}_{x}$ targets, and corresponding track diameter distributions, are presented in Figs 3 and 4, respectively. As it seen from Fig. 4 the track diameter distributions are significantly different. In the case of $\mathrm{TiH}_{x}$, there is a peak at $d=5-6 \mu \mathrm{m}$, corresponding apparently to protons with energies $\sim 2.5 \mathrm{MeV}$. The distribution in the case of $\mathrm{TiD}_{x}$ target is smoother and wider, with broad maximum at $d=7.5-9.0 \mu \mathrm{m}$. Obviously, in the latter case, the proton component is mixed with the tracks of accelerated deuterons.

One of the goals of our experiments was to initiate the dd-fusion in $\mathrm{TiD}_{x}$ target by laser beam irradiation. The detection of charged particle products of dd-reaction (3 MeV protons) was quite difficult, because of a large amount of background protons and deuterons accelerated up to $2-3 \mathrm{MeV}$. The signal from the $3 \mathrm{MeV}$ protons was separated from background only in the case of the detector 3-1 with a $25 \mu \mathrm{m}$ $\mathrm{Cu}$ filter placed behind the $\mathrm{TiD}_{x}$ target (see Table 1). The track diameter distributions for the detectors 3-1 (foreground) and 4-1 (background) are presented in Fig. 


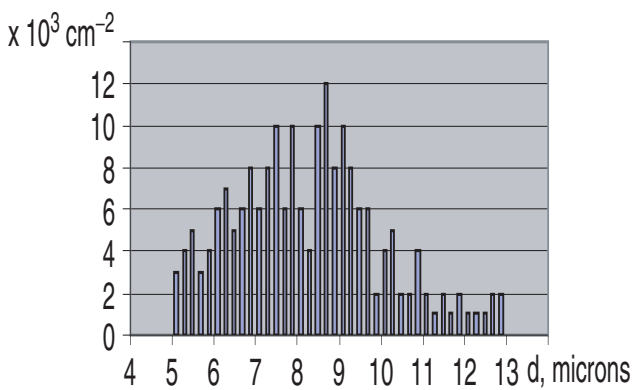

(a)

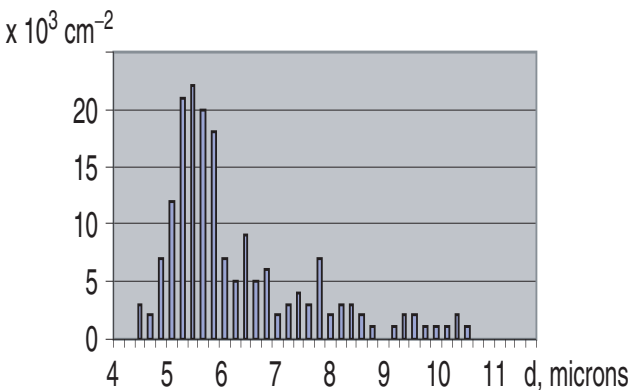

(b)

Figure 4. The track diameter distributions for the detectors showed in Fig. $3, S_{\text {det }}=1.4 \times$ $10^{-3} \mathrm{~cm}^{2}$, (a) $\mathrm{TiD}_{x}$ target and (b) $\mathrm{TiH}_{x}$ target.

$5 \mathrm{a}, \mathrm{b}$, respectively. In the case of $\operatorname{TiD}_{x}$ there is a peak at $d=5-7 \mu \mathrm{m}$, which may correspond to $3 \mathrm{MeV}$ protons penetrated the $25 \mu \mathrm{m} \mathrm{Cu}$ filter (Fig. 5a). The background distribution (Fig. 5b) contain only three events in the range $d=5-7 \mu \mathrm{m}$. Taking into account the detection efficiency, the $3 \mathrm{MeV}$ proton yield was estimated as $N_{\mathrm{p}}(\mathrm{dd}) \sim 10^{4}$ into $4 \pi$ sr per pulse. The measurements with In-based neutron activation detector showed a neutron yield $N_{\mathrm{n}}(\mathrm{dd})=2.3 \pm 0.8 \times 10^{4}$ into $4 \pi$ sr per pulse. Some difference between $N_{\mathrm{p}}(\mathrm{dd})$ and $N_{\mathrm{n}}(\mathrm{dd})$ is conditioned by the fact that the CR-39 detected the dd-protons only from a target depth which less than their mean-free-path in Ti.

It is important to note that the track density on the detectors is not uniform, and demonstrated an inhomogeneity in the accelerated field distribution. For example, a "ring structure" was detected on the detector placed behind the $\mathrm{TiH}_{x}$ target. Tracks with small diameters are placed close to the laser irradiation spot, and the tracks with lager diameters are placed on the concentrated cycles around the projection

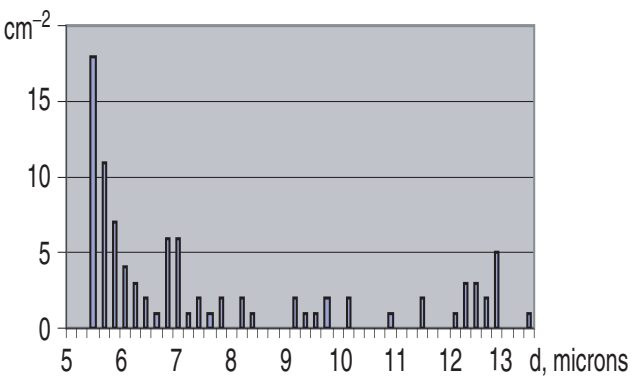

(a)

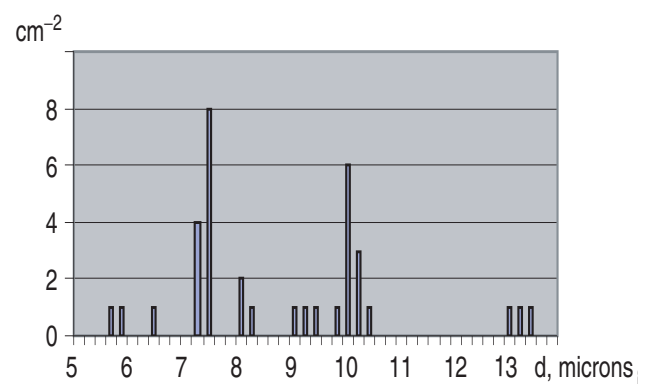

(b)

Figure 5. The track diameter distributions for the detectors exposed with the $25 \mu \mathrm{m} \mathrm{Cu}$ filter behind the target, $R=4 \mathrm{~cm}, \varphi=180^{\circ}, S_{\mathrm{det}}=0.8 \mathrm{~cm}^{2}$, (a) TiD target and (b) $\mathrm{TiH}_{x}$ target. 


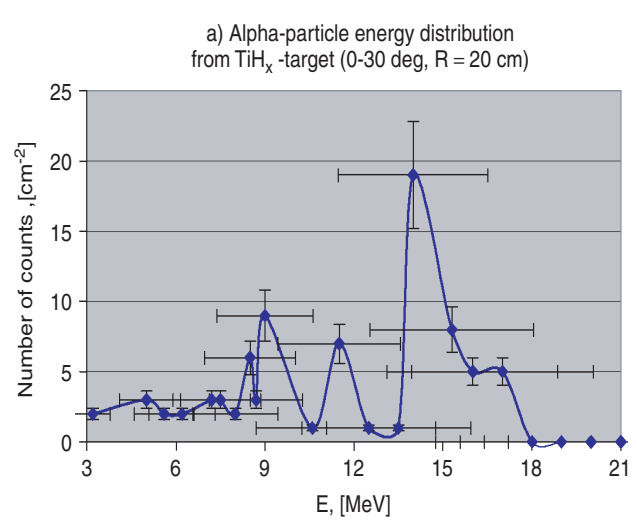

(a)

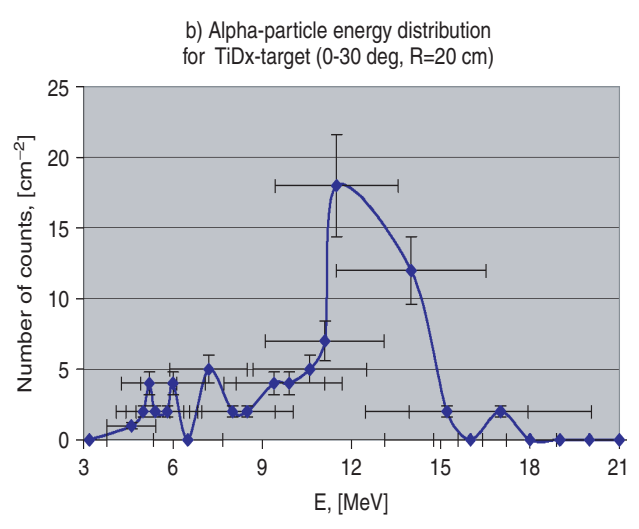

(b)

Figure 6. The $\alpha$-particle energy distributions, (a) $\mathrm{TiH}_{x}$ target and (b) $\mathrm{TiD}_{x}$ target.

of this spot on the detector surface.

According to the measurements with different filters, the maximum energy of protons and deuterons did not exceed 3.3 and $4.7 \mathrm{MeV}$, respectively. As seen from the distributions in Figs 4 and 5, there are some tracks with diameters $d=7$ $12 \mu \mathrm{m}$, which appear both on the open detectors and on the detectors with filters, with both $\mathrm{TiH}_{x}$ and $\mathrm{TiD}_{x}$ targets. According to the calibration, we associate these events with alpha particles accelerated up to $15 \mathrm{MeV}$. The associated alpha particle flux was estimated to be $\sim 10^{3}-10^{4} \mathrm{sr}^{-1}$ per pulse. No such $\alpha$-emission was observed in the case of $\mathrm{CH}_{2}$ targets. The energy spectra of the alpha particles, roughly reconstructed from distributions for the cases of $\mathrm{TiH}_{x}$ and $\mathrm{TiD}_{x}$ targets are presented in Fig. 6a,b, respectively. These spectra are quite similar, and the most of the alpha particles have energies in the range $10-16 \mathrm{MeV}$.

The emission of alpha particles has not been observed previously in laser irradiation experiments with solid (non-metal-hydride) targets. Note that similar proton and alpha emissions were detected during electrolysis experiments with thin metal film cathodes. ${ }^{10}$ Alpha emission $\left(E_{\alpha}=8-14 \mathrm{MeV}\right)$ was also observed during hydrogen (deuterium) desorption from $\mathrm{Au} / \mathrm{Pd} / \mathrm{PdO} / \mathrm{H}_{x}\left(\mathrm{D}_{x}\right)$ heterostructures. ${ }^{11}$

Alpha emission was observed from the surface of metals with large affinity to the hydrogen, in structures with large internal strains and under strong external influence. The absence of alpha emission in the case of $\mathrm{CH}_{2}$, and in other experiments with laser beam irradiation of targets with a small hydrogen affinity (such as $\mathrm{Al}$ and $\mathrm{Pb}^{8}$ ) may be connected with the small concentration of He in these materials. On the other hand, the alpha emission in our experiments may correspond to a large concentration of $\mathrm{He}$ on the surface of $\mathrm{TiH}_{x}$ and $\mathrm{TiD}_{x}$ targets, with the subsequent acceleration of these atoms in the plasma produced by the laser beam. The appearance of tracks with diameters $d>12 \mu$ m indicates the emission of ions with mass $A>4$. The energy of these ions, estimated with shielding filters, was found to be 
$E_{i} \geq 3 \mathrm{MeV}$ per nucleon. Unfortunately, the absence of calibration measurements with heavy ions was not allowed us to determine these particles accurately.

The generation of high-energy protons was investigated in [7] at the intensity of laser irradiation $\sim 10^{18} \mathrm{~W} / \mathrm{cm}^{2}$ and the duration of laser pulse of $130 \mathrm{fs}$. It was found, that the protons flying forward were accelerated up to an energy $\sim 2.2 \mathrm{MeV}$. It was also noted that the particle acceleration in laser-produced plasmas is a complex process, included the action of the ponderomotive force, the acceleration of ions by "hot" electrons and the "Coulomb explosion" of the plasma.

\section{Acknowledgments}

We are grateful to the scientific group of laser PROGRESS-P from the Research

Institute of Optic-electronic Devices and Systems (Sosnovyi Bor, Leningrad region, Russia) for the help in our experiments.

\section{References}

1. F.N. Beg, A.R. Bell, A.E. Dangor et al., Phys. Plasma 4(2), 447 (1997).

2. K. Krushelnick, E.L. Clark, M. Zepf etal., Phys. Plasma 7, 2055 (2000).

3. S.P. Hatchett, C.G. Brown, T.E. Govan et al., Phys. Plasma 7, 2076 (2000).

4. K. Nemoto, S. Banerjee, K. Flippo et al., Appl. Phys. Lett. 78, 955 (2001).

5. A. Maksimchuk, S. Gu, K. Flippo et al., Phys. Rev. Lett. 84, 4108 (2000).

6. A.P. Fews, P.A. Norrreys, F.N. Beg et al., Phys. Rev. Lett. 73, 1801 (1994).

7. S. Okihara et al., J. Nucl. Sci. Tech. 39, 1-5 (2002).

8. E.L. Clark, K. Krushelnick, M. Zepf et al., Phys. Rev. Lett. 85, 1654 (2000).

9. V.G. Borodin, V.M. Komarov, V.A. Malinov et al., Quantum Electron. 29, 101 (1999) (in Russian).

10. A.G. Lipson, A.S. Roussetski, C.H. Castano and J. Miley, Bull. Am. Phys. Soc. 47, 1219 (2002).

11. A.G. Lipson and A.S. Roussetski, Bulletin of the Lebedev Physics Institute, vol. 10, 22 (Russian Academy of Sciences, 2001). 